Original Articles

\title{
Clinical Efficacy and Safety of Rosuvastatin in Japanese Patients With Heterozygous Familial Hypercholesterolemia
}

\author{
Hiroshi Mabuchi ${ }^{1}$, Atsushi Nohara ${ }^{1}$, Toshinori Higashikata ${ }^{1}, K$ Kosei Ueda², Hideaki Bujo ${ }^{3}$, \\ Teruhiko Matsushima ${ }^{4}$, Yoshihiko Ikeda ${ }^{5}$, and Masahiro Nii ${ }^{6}$ \\ ${ }^{1}$ Kanazawa University, Ishikawa, Japan. \\ ${ }^{2}$ Komatsu Municipal Hospital, Ishikawa, Japan. \\ ${ }^{3}$ Chiba University, Chiba, Japan. \\ ${ }^{4}$ Tsukuba Memorial Hospital, Ibaraki, Japan. \\ ${ }^{5}$ Tagawa Municipal Hospital, Fukuoka, Japan. \\ ${ }^{6}$ AstraZeneca KK, Osaka, Japan.
}

\begin{abstract}
Rosuvastatin is a new statin that has been shown to produce substantial dose-dependent reductions in low-density lipoprotein cholesterol (LDL-C) in Western and Japanese hypercholesterolemic patients. Rosuvastatin efficacy and safety were assessed in an open-label, dose-titration trial of 37 Japanese patients with heterozygous familial hypercholesterolemia. After an 8-week dietary lead-in period, patients received rosuvastatin on the following schedule: $10 \mathrm{mg} /$ day during weeks $0-6 ; 20 \mathrm{mg} /$ day during weeks 6-12, and $40 \mathrm{mg} /$ day for weeks 12-18. Mean percentage reductions from baseline in LDL-C (49.2-56.7\%), total cholesterol (39.4-45.4\%), and non-high-density lipoprotein cholesterol (non-HDL-C) (46.7-54.3\%) were highly significant at each dose $(p<0.0001)$. Similar significant reductions in triglycerides $(18.2-25.0 \% ; p<0.006)$ and increases in HDL-C $(9.6-13.6 \% ; p<0.005)$ were observed. Rosuvastatin was well tolerated. Two patients withdrew from the study because of adverse events unrelated to the study treatment. No patients had clinically significant elevations in liver transaminases. Two patients exhibited a single increase in creatine kinase (one unrelated to study treatment, the other possibly related) with no muscle symptoms. Rosuvastatin produced significant beneficial changes in all lipid parameters in Japanese patients with heterozygous familial hypercholesterolemia and was well tolerated. $J$ Atheroscler Thromb, 2004; 11: 152-158.
\end{abstract}

Key words: Statin, HMG-CoA reductase inhibitor, Low-density lipoprotein cholesterol, Lipid-lowering

\section{Introduction}

Heterozygous familial hypercholesterolemia $(\mathrm{FH})$ is a common genetic disease associated with premature coronary artery disease. Approximately $85 \%$ of men with heterozygous $\mathrm{FH}$ experience an ischemic event before

Address for correspondence: Hiroshi Mabuchi, The Second Department of Internal Medicine, Kanazawa University Graduate School of Medical Science, 13-1 Takara-machi, Kanazawa 9208641, Japan.

E-mail: mabuchi@med.kanazawa-u.ac.jp

Received January 14, 2004.

Accepted for publication February 27, 2004. they reach 65 years of age, and if left untreated, $23 \%$ experience a fatal coronary event by 50 years of age (1, 2). Rosuvastatin (licensed to AstraZeneca, Alderley Park, Macclesfield, Cheshire, UK, from Shionogi and Company, Osaka, Japan) is a new statin with potent, dose-dependent low-density lipoprotein cholesterol (LDL-C)-lowering effects and beneficial effects on other elements of the lipid profile (3-10). In an 18-week, double-blind, multicenter trial (11), rosuvastatin was shown to provide significantly greater efficacy than atorvastatin in treating lipid abnormalities in Western patients with heterozygous FH. Two separate studies have demonstrated the clinical usefulness of rosuvastatin in treating Japanese hy- 
percholesterolemic patients $(12,13)$. In this paper, we present results from an open-label, dose-titration study on the efficacy and safety of rosuvastatin in Japanese patients with heterozygous $\mathrm{FH}$.

\section{Patients and Methods}

This open-label, dose-titration study was conducted at 13 centers in Japan between March 2000 and September 2002. Men and nonpregnant women who were 18 years of age or older were eligible for study participation if they met the following criteria: 1) known heterozygous $\mathrm{FH}$ (LDL-C level of $>190 \mathrm{mg} / \mathrm{dl}[4.9 \mathrm{mmol} / \mathrm{l}]$ or triglycerides of $>290 \mathrm{mg} / \mathrm{dl}[7.5 \mathrm{mmol} / \mathrm{l}]$; either tendon xanthomata [in themselves or in a first- or second-degree relative] or a first- or second-degree relative with confirmed $\mathrm{FH}$; and a documented heterozygous LDL receptor gene defect); or 2) clinically strongly suspected heterozygous $\mathrm{FH}$ (those meeting only the lipid criteria). To be eligible for receiving the study drug, all patients had to have fasting LDL-C levels, as determined by the Friedewald equation (14), of $\geq 220$ and $<500 \mathrm{mg} / \mathrm{dl}(\geq 5.69$ and $<12.93$ $\mathrm{mmol} / \mathrm{l}$ ), respectively, and fasting triglycerides of $\leq 400$ $\mathrm{mg} / \mathrm{dl}(\leq 4.52 \mathrm{mmol} / \mathrm{l})$ at the beginning and end of the 8week dietary lead-in period.

Exclusion criteria included a history of sensitivity to statins; serious or unstable medical or psychological conditions that could compromise the patient's safety or successful trial participation; a history of homozygous $\mathrm{FH}$; use of concomitant medications known to affect the lipid profile or present a potential safety concern; a history of drug or alcohol abuse; unexplained increases in creatine kinase to $>3 \times$ the upper limit of normal (ULN) during the dietary lead-in period; unexplained serum creatinine $>2.0 \mathrm{mg} / \mathrm{dl}(180 \mu \mathrm{mol} / \mathrm{l})$ during the dietary lead-in period; alanine transferase (ALT), aspartate aminotransferase (AST), or bilirubin values $>1.5 \times$ ULN during the dietary lead-in period; and participation in another investigational drug trial within 4 weeks of trial enrollment.

All participants gave informed consent before any trial procedure was initiated. The relevant institutional review boards approved the trial protocol and any amendments, and the trial was performed in accordance with the ethical principles consistent with good clinical practice and in accord with the Helsinki Declaration of 1975 as revised in 1983.

Patients successfully completing the dietary lead-in period received rosuvastatin for 18 weeks according to the following schedule: $10 \mathrm{mg} /$ day for the first 6 weeks, $20 \mathrm{mg} /$ day for the second 6 weeks, and $40 \mathrm{mg} /$ day for the third 6 weeks. The dose of rosuvastatin was not increased in patients with LDL-C levels $\leq 50 \mathrm{mg} / \mathrm{dl}(1.3$ $\mathrm{mmol} / \mathrm{l})$. At 18 weeks, patients were given the option to continue the current rosuvastatin dose for an additional 34 weeks (i.e., 52 weeks from the beginning of drug dos- ing). Only the 18-week data are presented in this paper. Blood samples were obtained after overnight fasting at weeks 1, 2, and 3 during the dietary lead-in period and at baseline and weeks $2,6,12$, and 18 during the titration period. All serum lipid assays, blood chemistries, fasting blood glucose tests, and urinalyses were performed by SRL Teijinbio Hachioji Laboratory in Tokyo. LDL-C levels were calculated from total cholesterol, highdensity lipoprotein cholesterol (HDL-C), and triglycerides, using the Friedewald equation (14). Total cholesterol and triglycerides were measured enzymatically. HDL-C was measured in the supernatant after precipitation of apolipoprotein (apo) B-containing lipoproteins by the heparin-Ca, Ni method. Apolipoproteins (apo A-I, B) were measured by turbidimetric immunoassay $(15,16)$.

The primary end point was mean percentage change in LDL-C level from baseline to 18 weeks. Baseline was the mean of the three values obtained during weeks 4,6 , and 8 of the lead-in period. All results shown are from the full analysis set (FAS), which included patients who received at least one dose of rosuvastatin and had at least one postbaseline value. The last observation was carried forward (LOCF) if the patient did not complete 18 weeks of treatment. Changes from baseline for all lipid parameters were tested, using a one-sample $t$-test (with a two-sided significance level of 0.05).

Safety assessments included recording of adverse events, hematologic and clinical chemistry measurements, and physical examinations. Adverse events were categorized according to an inventory based on the Coding Symbols for a Thesaurus of Adverse Reaction Terms (COSTART). All patients who received at least one dose of rosuvastatin were included in the safety analysis, and safety data are descriptively presented.

\section{Results}

Of the 76 patients entering the dietary lead-in phase, 37 patients received study treatment (the majority of those excluded failed to meet the lipid entry requirements). The demographic and baseline characteristics are listed in Table 1. In total, 30 patients had proven heterozygous $\mathrm{FH}(81.1 \%), 20$ patients were male $(54.1 \%)$, and the mean patient age was 51.8 years. Mean baseline LDL-C levels ranged from 211.0 to $444.7 \mathrm{mg} / \mathrm{dl}$.

A total of three patients withdrew from the study. Two patients withdrew because of adverse events, and one patient withdrew because of a protocol violation.

\section{Efficacy evaluation}

The lipid variables at baseline and mean change (the percent change) from baseline at 2, 6, 12, and 18 weeks are shown in Table 2. At 18 weeks, mean LDL-C levels decreased from 304.0 to $132.0 \mathrm{mg} / \mathrm{dl}$ (LOCF data; $56.7 \%$ reduction from baseline; $p<0.0001)$. Significant reduc- 
Table 1. Demographic and other characteristics at baseline.

\begin{tabular}{|c|c|}
\hline & Patients $(n=37)$ \\
\hline \multicolumn{2}{|l|}{ Age } \\
\hline Mean \pm SD $(y)$ & $51.8 \pm 11.4$ \\
\hline$\geq 65$ y (\%) & 13.5 \\
\hline \multicolumn{2}{|l|}{ Gender (\%) } \\
\hline Men & 54.1 \\
\hline Women & 45.9 \\
\hline \multicolumn{2}{|l|}{ Race (\%) } \\
\hline Japanese & 100 \\
\hline \multicolumn{2}{|l|}{ Weight (kg) } \\
\hline Mean \pm SD & $61.4 \pm 12.2$ \\
\hline \multicolumn{2}{|l|}{ Body mass index } \\
\hline Mean $\pm \mathrm{SD}\left(\mathrm{kg} / \mathrm{m}^{2}\right)$ & $23.4 \pm 3.05$ \\
\hline$>30(\%)$ & 2.7 \\
\hline \multicolumn{2}{|l|}{$\begin{array}{l}\text { Diagnosis of heterozygous familial } \\
\text { hypercholesterolemia (\%) }\end{array}$} \\
\hline Proven & 81.1 \\
\hline Clinically, strongly suspected & 18.9 \\
\hline \multicolumn{2}{|l|}{ Comorbid conditions (\%) } \\
\hline Diabetes & 10.8 \\
\hline Coronary heart disease & 21.6 \\
\hline
\end{tabular}

SD: standard deviation. tions in LDL-C levels were achieved as soon as 2 weeks after the start of therapy with rosuvastatin at $10 \mathrm{mg}$ (from 304.0 to $188.9 \mathrm{mg} / \mathrm{dl}$; $-38.5 \%$; $p<0.0001$ ) (Fig. 1). Additional significant reductions in LDL-C levels were achieved during each titration phase: from 304.0 to 156.4 $\mathrm{mg} / \mathrm{dl}(-49.2 \%)$ at week $6(p<0.0001)$ with rosuvastatin at $10 \mathrm{mg}$ and from 304.0 to $141.6 \mathrm{mg} / \mathrm{dl}(-53.9 \%)$ at week 12 ( $p<0.0001)$ with rosuvastatin at 10/20 mg. Reductions in total cholesterol ranged from $39.4 \%$ to $45.4 \%$ and were also significant compared with baseline $(p<$ $0.0001)$. Reductions in triglycerides were $18.2 \%$ at week 6 with rosuvastatin at $10 \mathrm{mg}(p<0.006), 23.6 \%$ with rosuvastatin at $10 / 20 \mathrm{mg}(p<0.0001)$ at week 12 , and $25.0 \%$ with rosuvastatin at $10 / 20 / 40 \mathrm{mg}(p<0.0001)$ at week 18 (LOCF data). Increases in HDL-C ranged from $9.6 \%$ to $13.8 \%$, with significant differences compared with baseline at the end of each dose titration phase $(p<$ 0.005). Highly significant reductions in non-HDL-C levels were also observed, ranging from $46.7 \%$ to $54.3 \%$ ( $p$ $<0.0001)$. Significant reductions were also seen in the LDL-C: HDL-C, total cholesterol: HDL-C, and non-HDLC: HDL-C ratios (Table $2 ; p<0.0001$ ). Rosuvastatin, at all dose levels, also significantly increased apo A-I levels

Table 2. Mean \% change from baseline in lipid parameters and ratios.

\begin{tabular}{|c|c|c|c|c|c|c|}
\hline & \multirow[b]{2}{*}{$\begin{array}{l}\text { Mean baseline } \\
\mathrm{mg} / \mathrm{dl} \pm \mathrm{SD}\end{array}$} & \multicolumn{5}{|c|}{ Rosuvastatin dose } \\
\hline & & $\begin{array}{c}10 \text { mg/day } \\
(\text { week } 2) \\
\mathrm{mg} / \mathrm{dl} \pm \mathrm{SD} \\
(\% \text { change } \pm \mathrm{SD})\end{array}$ & $\begin{array}{c}10 \mathrm{mg} / \text { day } \\
(\text { week 6) } \\
\mathrm{mg} / \mathrm{dl} \pm \mathrm{SD} \\
(\% \text { change } \pm \mathrm{SD})\end{array}$ & $\begin{array}{c}\text { 10/20 mg/day } \\
\text { (week 12) } \\
\text { mg/dl } \pm \text { SD } \\
\text { (\% change } \pm \text { SD) }\end{array}$ & $\begin{array}{c}\text { 10/20/40 mg/day } \\
(\text { week 18) } \\
\text { mg/dl } \pm \text { SD } \\
(\% \text { change } \pm \text { SD) }\end{array}$ & $\begin{array}{c}10 / 20 / 40 \mathrm{mg} / \text { day } \\
\text { (week 18/LOCF) } \\
\mathrm{mg} / \mathrm{dl} \pm \mathrm{SD} \\
(\% \text { change } \pm \mathrm{SD})\end{array}$ \\
\hline LDL-C & $304.0 \pm 49.2$ & $\begin{aligned} 188.9 & \pm 55.9 \\
(-38.5 & \pm 10.8)^{*}\end{aligned}$ & $\begin{array}{c}156.4 \pm 42.5 \\
(-49.2 \pm 10.0) *\end{array}$ & $\begin{array}{c}141.6 \pm 40.0 \\
(-53.9 \pm 10.1) *\end{array}$ & $\begin{array}{c}132.7 \pm 38.5 \\
(-56.7 \pm 10.3) *\end{array}$ & $\begin{aligned} 132.0 & \pm 37.0 \\
(-56.7 & \pm 9.9)^{*}\end{aligned}$ \\
\hline TC & $383.1 \pm 48.4$ & $\begin{array}{r}263.8 \pm 55.0 \\
(-31.4 \pm 8.5)^{*}\end{array}$ & $\begin{array}{r}233.5 \pm 41.7 \\
(-39.4 \pm 7.5)^{*}\end{array}$ & $\begin{array}{c}218.3 \pm 39.3 \\
(-43.3 \pm 7.8)^{*}\end{array}$ & $\begin{array}{r}211.4 \pm 39.9 \\
(-45.1 \pm 8.4)^{*}\end{array}$ & $\begin{array}{c}209.1 \pm 39.1 \\
(-45.4 \pm 8.2) *\end{array}$ \\
\hline HDL-C & $49.8 \pm 11.9$ & $\begin{array}{c}52.3 \pm 13.5 \\
(+5.8 \pm 11.5)^{* *}\end{array}$ & $\begin{array}{c}54.4 \pm 14.6 \\
(+9.6 \pm 13.9) * *\end{array}$ & $\begin{array}{c}56.4 \pm 13.6 \\
(+13.8 \pm 17.2) *\end{array}$ & $\begin{aligned} 57.5 & \pm 15.2 \\
(+13.7 & \pm 18.4)^{*}\end{aligned}$ & $\begin{aligned} 56.4 & \pm 15.2 \\
(+13.6 & \pm 17.8) *\end{aligned}$ \\
\hline Triglycerides & $146.7 \pm 73.3$ & $\begin{array}{c}113.4 \pm 50.5 \\
(-18.0 \pm 25.3) *\end{array}$ & $\begin{aligned} 114.3 & \pm 86.3 \\
(-18.2 & \pm 37.2) * * *\end{aligned}$ & $\begin{array}{c}101.3 \pm 43.1 \\
(-23.6 \pm 27.6) *\end{array}$ & $\begin{array}{c}106.4 \pm 59.9 \\
(-23.3 \pm 28.1)^{*}\end{array}$ & $\begin{array}{c}103.8 \pm 58.2 \\
(-25.0 \pm 27.7)^{*}\end{array}$ \\
\hline Non-HDL-C & $333.4 \pm 46.8$ & $\begin{array}{c}211.6 \pm 55.9 \\
(-37.1 \pm 10.2) *\end{array}$ & $\begin{array}{r}179.1 \pm 40.8 \\
(-46.7 \pm 8.8)^{\star}\end{array}$ & $\begin{array}{c}161.9 \pm 38.6 \\
(-51.8 \pm 9.3)^{*}\end{array}$ & $\begin{array}{c}153.9 \pm 40.0 \\
(-54.1 \pm 10.0) *\end{array}$ & $\begin{array}{r}152.7 \pm 38.5 \\
(-54.3 \pm 9.6)^{*}\end{array}$ \\
\hline LDL-C:HDL-C & $6.5 \pm 1.9$ & $\begin{aligned} 3.9 & \pm 1.6 \\
(-41.4 & \pm 11.5) *\end{aligned}$ & $\begin{array}{c}3.1 \pm 1.2 \\
(-53.1 \pm 11.1)^{*}\end{array}$ & $\begin{array}{c}2.7 \pm 1.1 \\
(-58.5 \pm 12.3) *\end{array}$ & $\begin{aligned} 2.5 & \pm 1.2 \\
(-60.8 & \pm 12.7)^{*}\end{aligned}$ & $\begin{aligned} 2.6 & \pm 1.2 \\
(-60.9 & \pm 12.2) *\end{aligned}$ \\
\hline TC:HDL-C & $8.1 \pm 2.0$ & $\begin{array}{c}5.3 \pm 1.7 \\
(-34.8 \pm 9.6)^{*}\end{array}$ & $\begin{array}{c}4.5 \pm 1.3 \\
(-44.1 \pm 9.6)^{*}\end{array}$ & $\begin{array}{c}4.1 \pm 1.1 \\
(-49.2 \pm 10.7)^{*}\end{array}$ & $\begin{aligned} 3.9 & \pm 1.4 \\
(-50.7 & \pm 10.9) *\end{aligned}$ & $\begin{aligned} 4.0 & \pm 1.3 \\
(-51.0 & \pm 10.6) *\end{aligned}$ \\
\hline Non-HDL-C:HDL-C & $7.1 \pm 2.0$ & $\begin{aligned} 4.3 & \pm 1.7 \\
(-40.1 & \pm 11.4) *\end{aligned}$ & $\begin{aligned} 3.5 & \pm 1.3 \\
(-50.7 & \pm 11.1) *\end{aligned}$ & $\begin{array}{c}3.1 \pm 1.1 \\
(-56.6 \pm 12.1) *\end{array}$ & $\begin{aligned} 2.9 & \pm 1.4 \\
(-58.6 & \pm 12.6) *\end{aligned}$ & $\begin{aligned} 3.0 & \pm 1.3 \\
(-58.7 & \pm 12.1) *\end{aligned}$ \\
\hline
\end{tabular}

HDL-C: high-density lipoprotein cholesterol, LDL-C: low-density lipoprotein cholesterol, SD: standard deviation, TC: total cholesterol. Patients received rosuvastatin on the following schedule: $10 \mathrm{mg} /$ day during weeks $0-6,20 \mathrm{mg} /$ day during weeks $6-12$, and $40 \mathrm{mg} / \mathrm{day}$ for weeks 12-18.

Week 18/LOCF : last observation carried forward analysis $(n=37)$ for week 18; all other data are from full analysis set (FAS).

$*: p<0.0001$ vs baseline, $* *: p<0.005$ vs baseline, $* * *: p<0.006$ vs baseline (one-sample $t$-test). 
and significantly decreased apo B levels and apo B:apo A-I ratios (Table 3; $p<0.0001$ ).

\section{Safety}

Treatment-emergent adverse events (events that occurred or worsened during the 18-week treatment administration period) occurred in 16 (43.2\%), 16 (43.2\%), and $15(41.7 \%)$ patients receiving $10,10 / 20$, and 10/20/ $40 \mathrm{mg}$ of rosuvastatin, respectively. A listing of the various categories of treatment-emergent adverse events is shown in Table 4. Two rosuvastatin patients (one each receiving 10/20 and 10/20/40 $\mathrm{mg}$ ) withdrew from the study because of adverse events. In each case, the event was considered unrelated to the study treatment.

Only one serious adverse event, intestinal obstruction, was noted in a patient receiving rosuvastatin at 10/20/

Table 3. Mean \% change from baseline in serum apolipoprotein levels and ratios at week 18.

\begin{tabular}{lccc}
\hline & $\begin{array}{c}\text { Mean baseline } \\
(\mathrm{mg} / \mathrm{dl} \pm \mathrm{SD})\end{array}$ & \multicolumn{2}{c}{$\mathrm{mg} / \mathrm{dl} \pm \mathrm{SD}$} \\
& $\%$ change $\pm \mathrm{SD})$ at week 18 \\
\hline Apo B & $219.1 \pm 34.2$ & $110.9 \pm 26.1$ & $(-49.3 \pm 9.6 *)$ \\
Apo A-I & $124.4 \pm 24.4$ & $142.8 \pm 9.9$ & $(+15.7 \pm 17.5 *)$ \\
Apo B:apo A-I & $1.84 \pm 0.53$ & $0.8 \pm 0.3$ & $(-55.2 \pm 11.1 *)$ \\
\hline
\end{tabular}

Apo: apolipoprotein, SD: standard deviation.

Patients received rosuvastatin on the following schedule: 10 $\mathrm{mg}$ /day during weeks 0-6, $20 \mathrm{mg} /$ day during weeks 6-12, and $40 \mathrm{mg} /$ day for weeks 12-18.

Last observation carried forward analysis $(n=37)$.

NB: apolipoprotein data were only collected at week 18 .

$*: p<0.0001$ vs baseline (one-sample $t$-test).

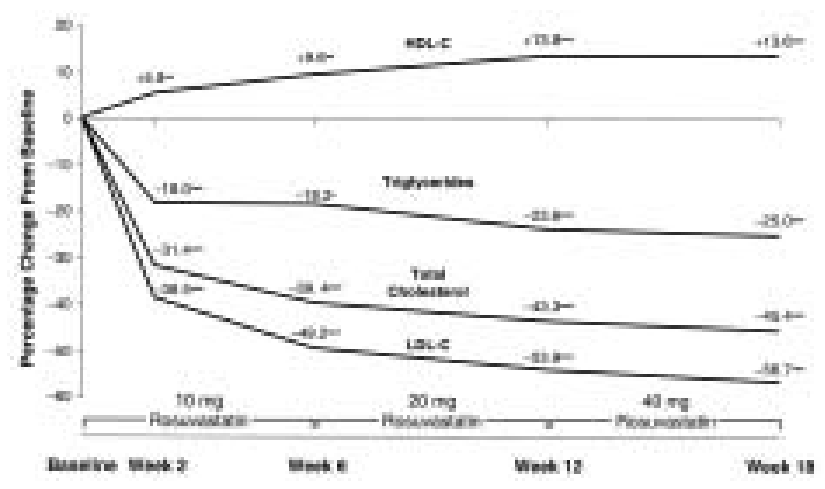

Fig. 1. Mean percentage change from baseline in LDL-C, total cholesterol, HDL-C, and triglycerides following titration to 10 and $20 \mathrm{mg}$ of rosuvastatin. *: $p<0.006$; **: $p<0.005$, ***: $p<$ 0.0001 vs baseline (one-sample $t$-test). Week 2,6 , and 12 data are from full analysis set (FAS). Week 18 data are last observation carried forward (LOCF, $n=37$ ).
$40 \mathrm{mg}$. The intestinal obstruction was considered to be associated with postoperative adhesions following recent abdominal surgery and not related to the study treatment. All other treatment-emergent adverse events were mild or moderate in severity. No patients demonstrated clinically relevant increases in ALT or AST (defined as values $>3 \times \mathrm{ULN}$ ). One patient receiving rosuvastatin at $10 \mathrm{mg}$ had a creatine kinase level $>10 \times$ ULN at week 6 . This patient had engaged in physical exercise the day prior to testing. Subsequent measurements were within normal limits, and this event was considered unrelated to study medication. Another patient receiving rosuvastatin at 10 $\mathrm{mg}$ had a creatine kinase level $>3 \times \mathrm{ULN}$ at week 6 ; this event was considered possibly related to the study treatment. There were no symptoms suggestive of muscle damage, and subsequent creatine kinase levels were within normal limits. No patients had clinically significant changes in lenticular opacity.

\section{Discussion}

This dose-titration study showed that rosuvastatin significantly reduces LDL-C in Japanese patients with heterozygous $\mathrm{FH}$ across a dose range of $10-40 \mathrm{mg}$. Titration from rosuvastatin at $10 \mathrm{mg}$ to the $20-\mathrm{mg}$ daily dose produced substantial improvements in all lipid parameters, including apolipoproteins and lipid ratios. Titration to the $40-\mathrm{mg}$ dose produced a small additional effect beyond that observed at $20 \mathrm{mg}$.

Table 4. Treatment-emergent* adverse events.

\begin{tabular}{|c|c|c|c|}
\hline & \multicolumn{3}{|c|}{$\begin{array}{c}\text { Rosuvastatin dose } \\
n(\%)\end{array}$} \\
\hline & $\begin{array}{c}10 \mathrm{mg} / \text { day } \\
\text { (week 6) } \\
n=37\end{array}$ & $\begin{array}{c}10 / 20 \mathrm{mg} / \text { day } \\
\text { (week 12) } \\
n=37\end{array}$ & $\begin{array}{c}\text { 10/20/40 mg/day } \\
\text { (week 18) } \\
n=36\end{array}$ \\
\hline Adverse events & $16(43.2 \%)$ & $16(43.2 \%)$ & $15(41.7 \%)$ \\
\hline Deaths & 0 & 0 & 0 \\
\hline $\begin{array}{l}\text { Serious adverse } \\
\text { events }\end{array}$ & 0 & 0 & $1(2.8 \%)$ \\
\hline $\begin{array}{l}\text { Adverse events } \\
\text { leading to } \\
\text { withdrawal }\end{array}$ & 0 & $1(2.7 \%)$ & $1(2.8 \%)$ \\
\hline $\begin{array}{l}\text { Treatment- } \\
\text { related adverse } \\
\text { events }^{\dagger}\end{array}$ & $3(8.1 \%)$ & 7 (18.9\%) & $5(13.9 \%)$ \\
\hline
\end{tabular}

Patients received rosuvastatin on the following schedule: $10 \mathrm{mg} /$ day during weeks $0-6,20 \mathrm{mg} /$ day during weeks $6-12$, and 40 $\mathrm{mg} /$ day for weeks 12-18.

*: Occurred or worsened during the 18-week treatment period.

$\uparrow$ : Treatment-emergent adverse events considered by the investigator to be related to study treatment. 
Patients with heterozygous FH typically have LDL-C levels that are 2 to 3 times above normal. Lifelong intervention is indicated, with statins being the mainstay of therapy. However, for the majority of these individuals, maximal doses of conventional statins are often needed, either alone or in combination with other therapies, to achieve lipid treatment goals. These additional therapies (e.g., bile acid sequestrants, ezetimibe, niacin, LDL apheresis) may be associated with poor tolerability or complex dosing schedules, or they may present a financial burden for many patients. These issues underscore the need for more potent and better-tolerated therapies for this difficult-to-treat genetic disorder.

The experience with statins in Japanese patients with $\mathrm{FH}$ is limited. A 24-week dose-titration study by Yamamura et al. examined the effects of atorvastatin at 10/20/40 mg/day in 88 Japanese FH patients and found mean LDL-C reductions from baseline of $38 \%, 44 \%$, and $48 \%$ with atorvastatin at 10,20 , and $40 \mathrm{mg}$, respectively (patients remained at each dose level for 8 weeks). Total cholesterol levels were reduced by $32 \%, 37 \%$, and $41 \%$, and HDL-C levels were increased by $9 \%, 7 \%$ and $6 \%$, respectively (17). Mabuchi et al. reported a mean $27 \%$ reduction in LDL-C $(p<0.001)$, a $21 \%$ reduction in total cholesterol $(p<0.001)$, and a $16 \%$ increase in HDL-C ( $p$ $<0.01$ ) in a population of 48 Japanese FH patients following 24 months of simvastatin therapy $(2.5,5$, or 10 $\mathrm{mg} /$ day) (18). More recently, the investigational agent pitavastatin was shown to produce a mean $44 \%$ reduction in LDL-C $(p<0.0001$, analysis of variance [ANOVA]), a $33 \%$ reduction in total cholesterol $(p<0.0001$, ANOVA), and a $6 \%$ increase in HDL-C $(p<0.035$, ANOVA) following 96 weeks of treatment in 25 Japanese patients with heterozygous $\mathrm{FH}$ (the dosage was $4 \mathrm{mg} /$ day, increased from $2 \mathrm{mg} /$ day after 8 weeks of therapy). Apo B was reduced by $34 \%(p<0.0001$, ANOVA), and apo A-I was increased by $12 \%$ ( $p=0.0002$, ANOVA) on this regimen (19).

Some insight into the clinical implications of the results for rosuvastatin from the current trial can also be gained from clinical studies in similar patient populations from different geographic regions. Most notable is a recent randomized, double-blind, dose-titration study in Western patients by Stein et al. that featured a similar design (i.e., dose titration every 6 weeks) and the same lipid entry criteria as the current study (11). A total of 623 patients with heterozygous $\mathrm{FH}$ were randomized to receive either rosuvastatin or atorvastatin at 20/40/80 mg daily. At 12 weeks (i.e., 40-mg dose), rosuvastatin was significantly more effective than atorvastatin in reducing LDL-C (54\% vs $46 \% ; p<0.001$, pairwise $t$-test) and total cholesterol (43\% vs $38 \% ; p<0.001$, pairwise $t$-test) and increasing HDL-C (10\% vs 3\%; $p<0.001$, pairwise $t$-test) levels. Rosuvastatin also produced significantly greater benefit $(p<0.001$, pairwise $t$-test) than atorvastatin on lipid ra- tios (LDL-C: HDL-C, total cholesterol: HDL-C, and nonHDL-C:HDL-C).

In our trial of Japanese patients, which used lower doses of rosuvastatin (10/20/40 mg daily) compared with those in the study by Stein and colleagues, quantitatively similar reductions from baseline at 12 and 18 weeks in LDLC (54-57\%), total cholesterol (43-45\%), and triglycerides (24-25\%) were observed. HDL-C was also increased at a similar percentage from baseline (14\%). In general, the results for rosuvastatin from the present study also show comparable or superior effects on the lipid profile of Japanese heterozygous $\mathrm{FH}$ patients compared with those reported for other statins. Although longer-term studies are needed, it is reasonable to expect that the beneficial effects of rosuvastatin we observed would extend beyond the 18 weeks of this study.

The safety profile of rosuvastatin has been extensively studied in a variety of patient populations (20). Overall, data from placebo-controlled trials have demonstrated that rosuvastatin is associated with similar rates of adverse events compared with placebo and similar low rates of withdrawal due to adverse events, consistent with the safety results for other statins. The administration of rosuvastatin at doses up to and including $40 \mathrm{mg}$ in this dose-titration study was well tolerated among Japanese patients with heterozygous $\mathrm{FH}$. Treatment-emergent adverse events, when they did occur, were mild or moderate in severity and similar in nature to those seen in previous studies of rosuvastatin (21). In addition, no patients had clinically significant elevations in serum transaminases or other findings suggesting clinically relevant effects on liver function, and there were no cases of myopathy (defined as creatine kinase $>10 \times$ ULN with muscle symptoms) or sustainable elevations in creatine kinase levels.

In conclusion, rosuvastatin is an effective new statin that produces substantial and significant reductions in LDL-C at doses of 10, 20, and $40 \mathrm{mg}$ in Japanese patients with heterozygous $\mathrm{FH}$. Rosuvastatin was well tolerated and did not produce any unanticipated adverse events.

Acknowledgments: We thank Koji Izuishi of AstraZeneca KK, Osaka, Japan, and Kristina Strutt and Aaron Dane of AstraZeneca, Cheshire, UK, for their contributions to this manuscript. In addition, we acknowledge the following study investigators: Akihiro Inazu, Kanazawa University, Ishikawa, Japan; Takeshi Kobayashi, Kaga Central Hospital, Ishikawa, Japan; Tadayoshi Takegoshi, Wajima Municipal Hospital, Ishikawa, Japan; Susumu Miyamoto, Himi Municipal Hospital, Toyama, Japan; Kuniyoshi Shimizu, Takaoka Hospital, Toyama, Japan; Senshu Hifumi, Hokuriku Central Hospital, Toyama, Japan; Tomoaki Saito, Itabashi Ward Medical Association Hospital, Tokyo, Japan; Kazuo Suzuki, Health House Suzuki 
Clinic, Tokyo, Japan; and Masahiro Tsuji, Hokkaido Social Insurance Hospital, Hokkaido, Japan. A full list of participating principal investigators and subinvestigators is presented in Appendix.

\section{References}

(1) Stone NJ, Levy RI, Fredrickson DS, and Verter J: Coronary artery disease in 116 kindred with familial type II hyperlipoproteinemia. Circulation, 49: 476-
488, 1974

(2) Goldstein JL and Brown MS: Familial hypercholesterolemia. In: The Metabolic Basis of Inherited Disease. 6th Ed, ed by Scriver CR, Beaudet AL, Sly WS and Valle D, pp 1215-1250, McGraw-Hill, New York, 1989

( 3 ) Paoletti R, Fahmy M, Mahla G, Mizan J, and Southworth H: Rosuvastatin demonstrates greater reduction of low-density lipoprotein cholesterol compared with pravastatin and simvastatin in

Appendix. List of principal investigators and subinvestigators by study site.

\begin{tabular}{|c|c|c|c|}
\hline Principal investigators* & Subinvestigators & Study sites & Department \\
\hline Atsushi Nohara & Akihiro Inazu & Kanazawa University & Internal Medicine II \\
\hline Toshinori Higashikata & $\begin{array}{l}\text { Yasunori Segawa } \\
\text { Atsushi Nohara }\end{array}$ & & \\
\hline Kosei Ueda & $\begin{array}{l}\text { Tatsuo Haraki } \\
\text { Toshio Tanahashi }\end{array}$ & $\begin{array}{l}\text { National Health Insurance } \\
\text { Komatsu Municipal Hospital }\end{array}$ & Internal Medicine \\
\hline Takeshi Kobayashi & $\begin{array}{l}\text { Yoshihito Kita } \\
\text { Kazuaki Mizutomi } \\
\text { Manabu Kitamura } \\
\text { Kenji Sakata } \\
\text { Asako Takemura } \\
\text { Toshiyuki Sukekawa } \\
\text { Yoshihisa Uetani } \\
\text { Fumihiko Kato } \\
\text { Takeshi Nozue }\end{array}$ & Kaga Central Hospital & Internal Medicine \\
\hline Tadayoshi Takegoshi & $\begin{array}{l}\text { Atsutoshi Hasegawa } \\
\text { Hiroshi Matsumoto } \\
\text { Yukari Iwaguchi }\end{array}$ & Wajima Municipal Hospital & Internal Medicine \\
\hline Susumu Miyamoto & Tsuyoshi Iwase & Himi Municipal Hospital & Internal Medicine \\
\hline Kuniyoshi Shimizu & $\begin{array}{l}\text { Tomio Kametani } \\
\text { Toshiyuki Kaneko }\end{array}$ & $\begin{array}{l}\text { Toyama Prefecture Welfare Association } \\
\text { Takaoka Hospital }\end{array}$ & Internal Medicine \\
\hline Senshu Hifumi & $\begin{array}{l}\text { Shuichi Hatakeyama } \\
\text { Katsuyuki Koichi } \\
\text { Shigeki Tagawa }\end{array}$ & $\begin{array}{l}\text { Mutual Aid Association of Public School Teachers } \\
\text { Hokuriku Central Hospital }\end{array}$ & Internal Medicine \\
\hline Yoshihiko Ikeda & $\begin{array}{l}\text { Hideaki Kondo } \\
\text { Yoko Tanaka } \\
\text { Keita Yamakawa } \\
\text { Masanori Motoda }\end{array}$ & Tagawa Municipal Hospital & Internal Medicine \\
\hline Hideaki Bujo & $\begin{array}{l}\text { Atsushi Mizota } \\
\text { Nao Asami }\end{array}$ & Chiba University & Internal Medicine II \\
\hline Teruhiko Matsushima & Noboru Shima & Tsukuba Memorial Hospital & Internal Medicine \\
\hline Tomoaki Saito & $\begin{array}{l}\text { Masaaki Kawamura } \\
\text { Jiro Takahashi }\end{array}$ & $\begin{array}{l}\text { Aggregate Corporation Itabashi Ward Medical } \\
\text { Association Hospital }\end{array}$ & Internal Medicine \\
\hline Kazuo Suzuki & - & Health House Suzuki Clinic & Internal Medicine \\
\hline Masahiro Tsuji & $\begin{array}{l}\text { Jun Ishii } \\
\text { Chifu Toyota } \\
\text { Hiroyuki Mizumoto }\end{array}$ & Hokkaido Social Insurance Hospital & Internal Medicine \\
\hline
\end{tabular}

*Dr. Atsushi Nohara was replaced by Dr. Toshinori Higashikata during the study. Dr. Nohara became a subinvestigator. 
hypercholesterolaemic patients: a randomized, double-blind study. J Cardiovasc Risk, 8: 383-390, 2001

( 4 ) Davidson M, Ma P, Stein EA, Gotto AM Jr, Raza A, Chitra R, and Hutchinson $\mathrm{H}$ : Comparison of effects on low-density lipoprotein cholesterol and highdensity lipoprotein cholesterol with rosuvastatin versus atorvastatin in patients with type Ila or Ilb hypercholesterolemia. Am J Cardiol, 89: 268-275, 2002

( 5 ) Olsson AG, McTaggart F, and Raza A: Rosuvastatin: a highly effective new HMG-CoA reductase inhibitor. Cardiovasc Drug Rev, 20: 303-328, 2002

(6) Olsson AG, Istad H, Luurila O, Ose L, Stender S, Tuomilehto J, Wiklund O, Southworth $\mathrm{H}$, Pears J, and Wilpshaar JW, for the Rosuvastatin Investigators Group: Effects of rosuvastatin and atorvastatin compared over 52 weeks of treatment in patients with hypercholesterolemia. Am Heart J, 144: 10441051, 2002

( 7 ) Brown WV, Bays HE, Hassman DR, McKenney J, Chitra $\mathrm{R}$, Hutchinson $\mathrm{H}$, and Miller $\mathrm{E}$, for the Rosuvastatin Study Group: Efficacy and safety of rosuvastatin compared with pravastatin and simvastatin in patients with hypercholesterolemia: a randomized, double-blind, 52-week trial. Am Heart J, 144: 1036-1043, 2002

(8) Schneck DW, Knopp RH, Ballantyne CM, McPherson R, Chitra RR, and Simonson SG: Comparative effects of rosuvastatin and atorvastatin across their dose ranges in patients with hypercholesterolemia and without active arterial disease. Am J Cardiol, 91: 33-41, 2003

( 9 ) Blasetto JW, Stein EA, Brown WV, Chitra R, and Raza A: Efficacy of rosuvastatin compared with other statins at selected starting doses in hypercholesterolemic patients and in special population groups. Am J Cardiol, 91(suppl): 3C-10C, 2003

(10) Jones $\mathrm{PH}$, Davidson MH, Stein EA, Bays HE, McKenney JM, Miller E, Cain VA, and Blasetto JW, for the STELLAR Study Group: Comparison of efficacy and safety of rosuvastatin versus atorvastatin, simvastatin, and pravastatin across doses (STELLAR Trial). Am J Cardiol, 92: 152-160, 2003

(11) Stein E, Strutt KL, Southworth H, Diggle PJ, and Miller E, for the HeFH Study Group: Rosuvastatin compared with atorvastatin in patients with heterozygous familial hypercholesterolemia: a randomized trial. Am J Cardiol, 92: 1287-1293, 2003

(12) Yamamoto A, Arakawa K, Sasaki J, Matsuzawa Y, Takemura K, Tsushima M, Fujinami T, Mabuchi H,
Itakura $\mathrm{H}$, Yamada $\mathrm{N}$, and Toyota $\mathrm{T}$, for the Rosuvastatin Dose-Ranging Trialist Group: Clinical effects of rosuvastatin, a new HMG-CoA reductase inhibitor, in Japanese patients with primary hypercholesterolemia: an early phase II study. J Atheroscler Thromb, 9: 48-56, 2002

(13) Saito Y, Goto Y, Dane A, Strutt K, and Raza A, for the Japan Rosuvastatin Study Group: Randomized dose-response study of rosuvastatin in Japanese patients with hypercholesterolemia. J Atheroscler Thromb, 10: 329-336, 2003

(14) Friedewald WT, Levy RI, and Fredrickson DS: Estimation of the concentration of low-density lipoprotein cholesterol in plasma, without use of the preparative ultracentrifuge. Clin Chem, 18: 499-502, 1972

(15) Ikeda T, Shibuya Y, Senba U, Sugiuchi H, Araki S, Uji $\mathrm{Y}$, and Okabe $\mathrm{H}$ : Automated immunoturbidimetric analysis of six plasma apolipoproteins: correlation with radial immunodiffusion assays. J Clin Lab Anal, 5: 90-95, 1991

(16) Blum CB: Comparison of properties of four inhibitors of 3-hydroxy-3-methylglutaryl-coenzyme A reductase. Am J Cardiol, 73: 3D-11D, 1994

(17) Yamamura T, Oikawa S, Saito Y, Mabuchi H, Matsuzawa Y, Ohashi Y, and Yamamoto A: Clinical efficacy of $\mathrm{Cl}-981$ (atorvastatin) with familial hypercholesterolemia. J Clin Ther Med, 14: 2031-2054, 1998 (in Japanese)

(18) Mabuchi H, Koizumi J, Fujita H, Uno Y, Kamon N, Watanabe A, Kajinami K, Miyamoto S, Yoshimura A, Ueda K, Sakai K, Ohta M, Kato M, Kametani T, Takegoshi T, Haba T, Wakusugi R, and Takeda R: Clinical efficacy of MK-733 (simvastatin) in longterm treatment with familial hypercholesterolemia. J Clin Ther Med, 6: 519-540, 1990 (in Japanese)

(19) Noji Y, Higashikata T, Inazu A, Nohara A, Ueda K, Miyamoto S, Kajinami K, Takegoshi T, Koizumi J, and Mabuchi $\mathrm{H}$, for the Hokuriku NK-104 Study Group: Long-term treatment with pitavastatin (NK104), a new HMG-CoA reductase inhibitor, of patients with heterozygous familial hypercholesterolemia. Atherosclerosis, 163: 157-164, 2002

(20) Schuster H: Rosuvastatin-a highly effective new 3hydroxy-3-methylglutaryl coenzyme A reductase inhibitor: review of clinical trial data at $10-40 \mathrm{mg}$ doses in dyslipidemic patients. Cardiology, 99: 126-139, 2003

(21) Brewer HB: Benefit-risk assessment of rosuvastatin 10 to 40 milligrams. Am J Cardiol, 92 (suppl 4B): 23K-29K, 2003 